Full-text Available Online at www.ajol.info and www.bioline.org.br/ja
J. Appl. Sci. Environ. Manage. March, 2015

Vol. 19 (1) 161 - 166

\title{
Some Advice about the Water Strategy of China to Keep the Water Balance in 2025
}

\author{
*1'XIANGLONG WEI ${ }^{1}$, WANQIN XIE ${ }^{2}$, JINLING XU $^{1}$, \\ ${ }^{I}$ School of River \& Ocean Engineering, Chongqing Jiaotong University, Chongqing, China \\ ${ }^{2}$ International College, Chongqing Jiaotong University, Chongqing, China \\ "Corresponding author e-mail: 90wxl@sina.cn,
}

KEY WORDS: Water Strategy, Water Demand, Math Models

\begin{abstract}
Water resource is crucial for human survival. And fresh-water is the constraint for the development of China. In order to realize the sustainable development, we build three mathematical models for determining an effective, feasible and cost-efficient water strategy to meet the projected water demand of China in 2025. These models are as following: model of the cost of water transfer, model of the water price and the model of desalination plant construction cost. All the models are based on the forecast of the water demand and supply of China in 2025. Based on the result of these models, we propose some advice about the water strategy to meet the water demand of China in 2025, such as: building desalination plants in the coastal provinces which are lack of water, carrying out the inter-basin water transfer projects in the middle of China, setting a reasonable water price based on the market economy and et al.@JASEM
\end{abstract}

http://dx.doi.org/10.4314/jasem.v19i1.21

Introduction: Water shortage is a common and complex phenomenon in real life, so it's very urgent for every country to make an effective, feasible and cost-efficient water strategy to meet the projected water. As for China, China is faced with a serious shortage of freshwater now. The water resources in the south are abundant, but the north part is lack of water. The spatial distributions are not reasonable. Meanwhile, the total amount of water is huge, but the amount of per capita water smaller than many other countries. In addition, because of the environmental issue, a large amount of water is seriously polluted. So, a lot work has to be done to help the decision makers to choose the best way to meet the water demand, especially for China.

In this paper, we are going to discuss the feasibility of methods for making a water strategy in the mainland of China, based on the forecasting result of the water demand and supply of China in 2025 (Wei et al.,2015). As previous research showing, it's much easier and more accurate to solve the water-shortage of a small scale, such as the water strategy used in the coastal Binhai New Area (Li et al.,2014), so as for the mainland of China, some factors should be ignored. As concerned of the measures of the water strategy, trans-valley water diversion projects and the desalinization of saline water are acceptable in certain cases (Essink 2001).

\section{MODELS OF THE WATER STRATEGY}

Based on result of the previous research (Wei et al., 2015), the value of water shortage in 2025 can be provided, shown as show as table 1 . By analyzing the result, it is obvious that whether the province is short of water or not.

Table 1: Water Deficit $\left(10^{6} \mathrm{~m}^{3}\right)$

\begin{tabular}{ll|ll}
\hline Location & Amount & Location & Amount \\
\hline Nation & 9.7357 & Liaoning & 0.32433 \\
Anhui & -1.36416 & Neimeng & 5.93909 \\
Beijing & -0.17634 & Ningxia & -0.54282 \\
Fujian & 0.14167 & Qinghai & 3.03448 \\
Gansu & -1.12577 & Shandong & -1.96515 \\
Guangdong & 2.01683 & Shanxi & -0.34265 \\
Guangxi & 3.89444 & Shangxi & 1.76763 \\
Guizhou & 2.0939 & Shanghai & -1.05745 \\
Hainan & 2.36669 & Sichuan & -1.17338 \\
Hebei & 0.92866 & Tianjin & -0.18657 \\
Henan & -1.27408 & Xizang & 4.22346 \\
Heilongjiang & -3.02279 & Xinjiang & 0.99809 \\
Hubei & -1.37109 & Yunnan & -0.06422 \\
Hunan & 0.47021 & Zhejiang & 0.38041 \\
Jilin & -0.33308 & Chongqing & 0.85319 \\
Jiangsu & -3.72558 & Jiangxi & -1.39696 \\
\hline
\end{tabular}

As shown in table 1, in the view of the nation, China is not short of water. But as for every province, the conclusion is different. So some measures should be taken to satisfy the need of water in the provinces which are lack of water. 
To solve the problem of water shortage, we have two approaches. One way is inter-basin water transfer. Large-scale inter-basin water transfer (IBWT) projects are commonly proposed as solutions to water distribution and supply problems (Grant, 2012). The inter-basin water transfer project is an alternative to balance the temporal and spatial distribution of water resources and water demands, especially in arid and semi-arid regions. A water transfer project can be executed if it is environmentally and economically justified (Karamouz et al., 2010). The other one is desalinization of salt water. We can find which one is much better based on the fee of the two approaches, or combine them.

The table 1 shows that the water of nation is enough. For Xinjiang and Qinghai, which are located in northwestern China with precipitation usually less than $200 \mathrm{~mm}$, they belong to water-rich regions due to the small population density there (Wang, 2014). Therefore, a lot of factors impact the result, and these factors must be considered to analyze the situation of water shortage. In order to take the feasible actions, the whole of China can be divided into two parts. One part contains the all provinces of surplus water and the other part includes the all provinces which has the water shortage.

\section{Model of the Cost of Water Transfer Assumption}

1. Water of every province is focused on the provincial capital city.

2. For making the problem simpler, all the water is transferred through the pipeline instead of the nature river.

3. All the route between cities is line.

4. The price of the pipeline is invariable.

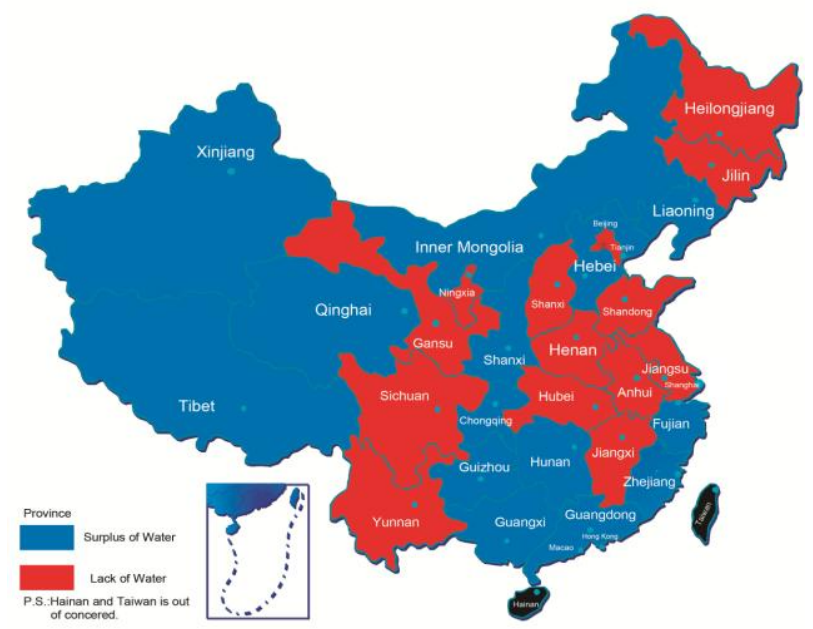

Fig 1: The water demand of Chinese mainland in 2025
Model Foundation: The model is used to obtain the least cost of water transfer. At first, according to the distance between cities, we can calculate the minimum of distance of water transfer. The whole of China is divided into 16 water-deficient areas and 14 watering areas. According to the distance between different provinces and value of the water shortage, the model can be established as follows:

$$
\begin{aligned}
& X=\operatorname{Min} \sum_{\mathrm{i}=1}^{30} \sum_{\mathrm{j}=1}^{30} A_{i j} \\
& \sum_{\mathrm{i}=1}^{30} B_{\mathrm{ij}} \geq B_{\mathrm{j}}, \quad \mathrm{i} \neq \mathrm{j}
\end{aligned}
$$

$A_{\mathrm{ij}}$ : The distance between province $\mathrm{i}$ and $\mathrm{j}$

$B_{\mathrm{ij}}$ : The transfer water from the city of $\mathrm{i}$ to the city of $\mathrm{j}$.

$B_{\mathrm{j}}$ : The water-deficient weight of the city of $\mathrm{j}$.

The optimal model is solved by bubble sorting. Owing to this reason, we name it the Optimal Model of Bubble Sorting.

Solution and Result: We use the bubble sorting to solve this model. Using this algorithm, we can get the sequence of the minimum value. 16 water-deficient provinces and 14 watering provinces make up the series. At first, we find the minimum from the series with bubble sorting. Second, the series get rid of the array that contains the minimum. Then the new series can be obtained. With circulating this process, the all minimum can be gotten. The preliminary location of minimum is confirmed with the Find Function in MATLAB. The minimum is the least distance between water-deficient provinces and watering provinces. Now, the preliminary transfer roads are shown as figure 2:

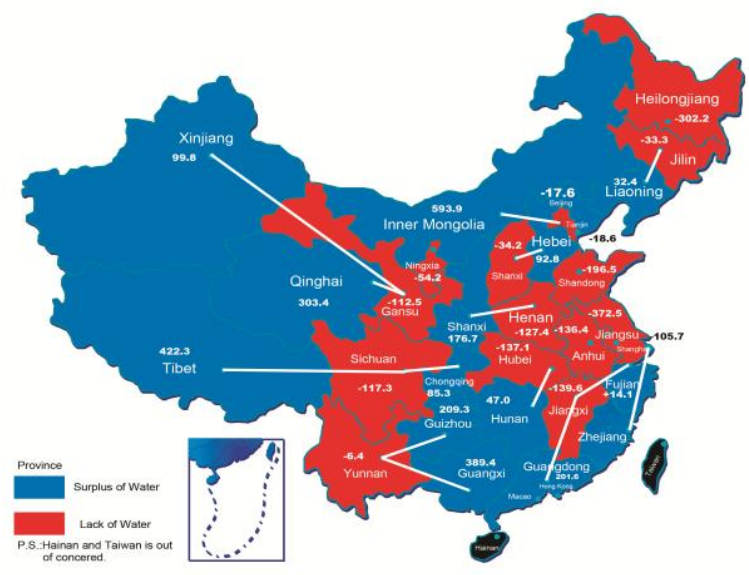

Fig 2 Preliminary transfer roads 
Based on the acquired result and the water shortage, the more precise transfer routes can be gotten, too. The result is shown as figure 3 :

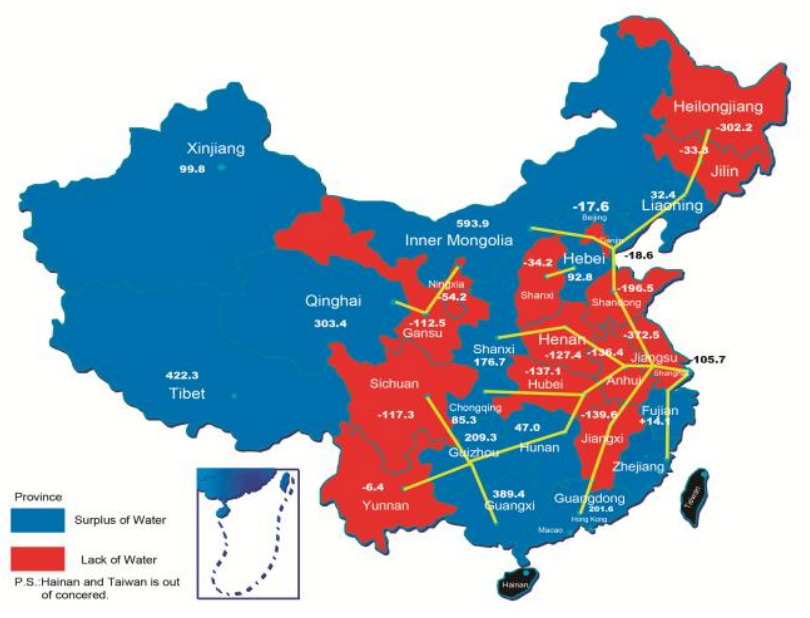

Fig 3: New transfer roads

The transfer routes are not the last result, and the transfer cost is final result we want. The advisory price of the Chinese pipeline investment is 2.5 million RMB $/ \mathrm{km}$ (Yao et al., 2005), so it goes to this:

$$
\sum 13478 \times 2.5=33 \text { billion RMB }
$$

Evaluation of the model: With the help of this model, we can find the most reasonable routes of transfer water. In addition, the cost (per year) of transfer water can be calculated according to the model. Meanwhile, we ignore the factors of terrain and environment, since it's really too complicated to find the standard of valuation.

\section{Model of Water Price}

With the help of the previous models, the distribution of the water between different provinces has been solved. And in this model, we will work out a feasible way to optimize the allocation of the water resources by setting a reasonable water price.

Considering the allocation of the water resources and the varying amount of the rainfall, we improved the Two-part Water Price Model (Liu et al., 2009) to work out an appropriate water price for every province.

\section{Assumption}

1. The water price in the same province is the same.

2. The pipes between different provinces are big enough to transfer any amount of water at the same time from different directions.

3. The cost of this pipe system is only determined by the length of the pipe.

4. The projected water price is only related to the cost of the pipe system, and they are linear correlated.

Model Foundation: The ultimate water price is determined by the cost of the pipe system, scot, profits and the cost of sewage treatment (Liu et al., 2009). And then, a mathematical model is built as fallowed:

$$
\begin{aligned}
& P=P_{b}+P_{a} \\
& P_{a}=k * P_{c}+b
\end{aligned}
$$

$p$ is the total water price, $P_{b}$ is the basic water price, and $P_{b}$ is fixed value in a fixed province, $P_{a}$ is the project water price, $k$ and $b$ are two coefficient.

Solution and Result: In model 1, the optimal path layout has been solved, and the distance (the length of the pipe) between different provinces is available, using the data we got and obeying some related rules, we can work out the value of the projected water price and the basic water price. So it's convenient to determine the strategy of the water allocation and calculate the total water price in every province.

Evaluation of the model: In this model, the projected water price is determined by the length of the pipe, so it's convenient to determine the quantity of the water getting from other provinces. Meanwhile, this model offers a simple way to estimate the value of the projected water price. Moreover, some useful conclusions about the price and the quantity of transporting the water have been drawn. And all the points above is gotten on the base of simplifying the inter-basin water transfer. Meanwhile, because the process of calculating $P_{b}$ is simplified, the result is inaccurate in some way, and this model is just applied to some ideal condition, so we should improve it for widely use.

\section{Desalinization Model}

\section{Assumption}

1. We will not experience the mass of human activities or natural disasters that can impact the model.

2. The unit cost is same in different areas.

3. The route between two provinces is the straight.

Model Foundation: If the freshwater is shortage, and the province is a coastal province at the same time, then we can desalinate sea water to get more freshwater. So we build a model to calculate the cost of 
desalination.

$$
C=N y+M x
$$

$C$ : The total cost of desalination. $\left(10^{8}\right)$

$N$ : Number of plants to be constructed in 2025 .

$M$ : Water production by a desalination plant per day

$x$ : Treatment cost of desalination per cubic meter in 2025(RMB)

$y$ : Average construction fee (RMB) of a desalination plant in 2025(hundred million)

Based on the previous research (Gao , 2012) we find:

$x^{\prime}=7$ : Cost of desalination per cubic meter in 2009 (RMB).

$M^{\prime}=10000$ : Water production by a desalination plant per day (cubic meter).

$y=2.5$ : Average construction fee of a desalination plant in 2025 (hundred million)

With the continuous development of science and technology, the production of a desalination plant per day will increase. Instead, the cost of desalination per cubic meter will reduce. According to historical data, we assume:

(1) Desalinating $1 \mathrm{~m}^{3}$ of sea water can get $1 \mathrm{~m}^{3}$ of freshwater.

(2) The cost of desalination declines at a rate of $5 \%$.

(3) The production of a desalination plant per day increases at a rate of $5 \%$.

So:

$$
\begin{gathered}
M=10000 \times(1+5 \%)^{\wedge}(2025-2009)=21828 \\
x=7 \times(1-5 \%)^{\wedge}(2025-2009)=3.08
\end{gathered}
$$

From model 2, we can know these provinces which are short of water. As table:
Table 2: The amount of water shortage in each province

\begin{tabular}{lc}
\hline Province & Water shortage $\left(\mathbf{m}^{3}\right)$ \\
\hline Anhui & 1364163 \\
Beijing & 1364163 \\
Gansu & 1364163 \\
Henan & 1364163 \\
Heilongjiang & 1364163 \\
Hubei & 1364163 \\
Jilin & 1364163 \\
Jiangsu & 1364163 \\
Ningxia & 542820 \\
Shandong & 1965148 \\
Shanxi & 342653.6 \\
Shanghai & 1057448 \\
Sichuan & 1173385 \\
Tianjin & 186574 \\
Yunnan & 64215.82 \\
Jiangxi & 1396959 \\
Total & 17642507 \\
\hline
\end{tabular}

From the table 2, we can know:

The total amount of water shortage $=17642507\left(\mathrm{~m}^{3}\right)$

So:

$$
M \times 365 \times N=17642507
$$

Plugging $M=21828.7$ into the equation for above, we obtain:

$$
\begin{aligned}
& 21828.7 \times 365 \times N=17642507 \\
& \text { Then : } \quad N=2.21
\end{aligned}
$$

In order to meet the need of water, and $\mathrm{N}$ must be integer. Then:

$$
N=3 \text {. }
$$

So:

$$
C=8.04
$$

We can know that the cost of desalination is 8.04 hundred million (RMB).

Analysis of the result: Comparing the result with model 3, we can get: supplying the same amount of freshwater, the cost of desalination is less than water transfer. So, we should pay more attention to desalination, which is more useful for solving the water shortage problem. 
Evaluation of the model: A corresponding strength of the model is that it would be relatively easy to calculate the cost of desalination. While, this model just applies to the problem with steady data. If we want to apply it to reality, the model must be improved.

From the result of the Desalinization Model, we can see that it's much cheaper to build the desalination plant than inter-basin transfer. The core of the ultimate strategy is to build desalination plant in the coastal provinces which are lack of water. Then these provinces can be regarded as the provinces of exporting the water. Now provinces lack of water is

\section{RESULTS AND CONCLUSIONS}

Results: To meet the water needs of China in 2025, we combine these models and make a best water strategy for China.

less, it's much easier to optimize pipes path. After using the bubble sort, we get a preliminary optimization of transfer path. Basing on the real amount of water supply in every province, we optimize the preliminary layout of the pipes. Finally, the layout of pipes and desalination plants are shown on the same picture:

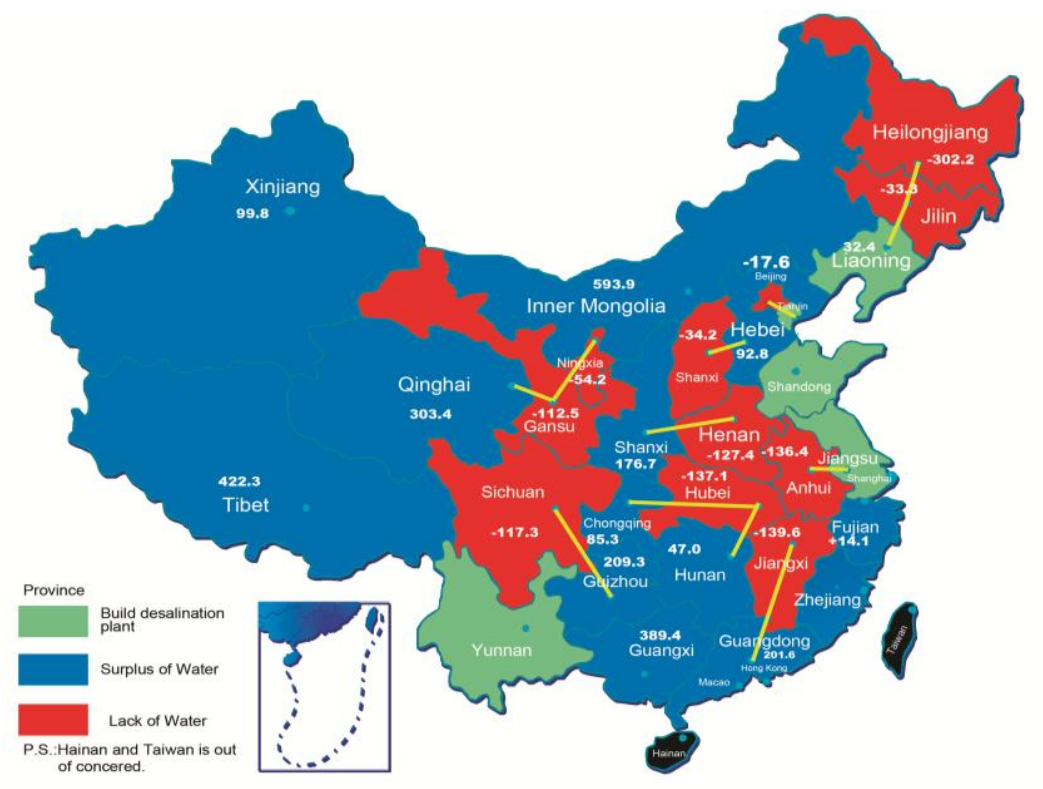

Fig 4: The layout of pipes and desalination plants

Conclusions: With China's population increasing, and the rapid development of industry and agriculture, the problem of water-shortage is getting worse. In order to achieve sustainable development, the decision makers should carry out a right water strategy to solve this problem.

In this paper, we propose some advice on the base of the results of the models, as follows. Building desalination plants in the coastal provinces which are lack of water can ease the situation getting worse. And in the middle of China, more water diversion projects should be constructed between the provinces, balancing the temporal and spatial distributions of the freshwater. Meanwhile, setting a reasonable water price based on the market economy is an effective to protect the water resource for the decision makers. In addition, publicize the sense of Water conservation widely among the people. These advices are not just for solving the water shortage. By building these desalination plants and constructing the water diversion projects, more jobs are available, and the economy is further developed. These projects can also develop situation of the infrastructure.

The models are formulated based on the data of previous years, while we ignore the factors of terrain, environment and et al., because of the complication and feasibility. As for inter-basin water transfer, we simplify the transfer method, applying to some ideal condition. Therefore, the result is not appropriate enough for all regions and all conditions, so further research to address this is needed.

\section{REFERENCES}

EGrant, E. H. C., Lynch, H. J., Muneepeerakul, R., Arunachalam, M., Rodríguez-Iturbe, I., \& Fagan, 
W. F. (2012) . Interbasin water transfer, riverine connectivity, and spatial controls on fish biodiversity. PloS one, 7(3): e34170.

Gao, C.J. (2012). Simple Analysis of the Desalination Development of Sea Water . Water \& Wastewater Information, (1): 11-13

Karamouz, M., Mojahedi, S. A., \& Ahmadi, A. (2009). Interbasin water transfer: economic water quality-based model. Journal of irrigation and drainage engineering, 136(2): 90-98.

Li, X., Zhao, Y., Shi, C., Sha, J., Wang, Z. L., \& Wang, Y. (2015). Application of Water Evaluation and Planning (WEAP) model for water resources management strategy estimation in coastal Binhai New Area, China . Ocean \& Coastal Management, 106:97-109.

Liu W.G. and Zheng C.Y. (2009). Two-part Water Price Model of the South-to-North Water Diversion Project Based on Quota of Water Consumption. CHINA POPULATION, RESOURCES AND ENVIRONMENT, 19(4):47-49
Wang, Y. B., Wu, P. T., Zhao, X. N., \& Engel, B. A. (2014). Virtual water flows of grain within China and its impact on water resource and grain $\begin{array}{lll}\text { security in 2010. Ecological } & \end{array}$ Engineering, 69:255-264.

Wei X.L., Xu J.L., Zhai Y.Y. (2015). Forecasting Water Demand and Supply of China for 2025 . AFRREV STECH: An International Journal of Science and Technology, 4(1):1-15.

Yao Qingyun,Li JIaqi (2005).The Economical Calculations of Diameter in Pressure Pipe . China Rural Water and Hydropower, 2005, 4:56-57. 